Upsala J Med Sci 93: 101-120, 1988

\title{
The Relationship between the Pharmacokinetics and Pharmacodynamics of Spinal Opioids
}

\author{
Minireview based on a doctoral thesis \\ Staffan Sjöström \\ Department of Anesthesiology and Intensive Care, University Hospital, Uppsala, Sweden
}

\begin{abstract}
Spinal opioids have been used clinically since the late seventies to treat acute, traumatic, obstetric and chronic pain. In this article the influence of the pharmacokinetics on the dynamics of intrathecal and epidural opioid administration are discussed with reference to current knowledge.
\end{abstract}

\section{INTRODUCTION}

During the last two decades knowledge has increased about the physiology of pain and the mechanisms of pain relief from opioids. Martin's postulation in 1967 (63) on the existence of opioid receptors in the nervous system was confirmed in 1973 (75,90,99). Two years later Hughes and co-workers isolated the first endogenous opioids (44). Within a year, evidence of analgesia in rats after intrathecal morphine was also provided by Yaksh and Rudy (110). In 1979 Wang et al. published a study demonstrating clear evidence of pain relief from intrathecal morphine in humans (104). Also in 1979 Behar et al. described pain relief from epidural morphine in patients with acute and chronic pain (4). In the same year Cousins et al. reported that pain relief from epidural pethidine correlated with cerebrospinal fluid (CSF) concentrations of the drug but not with plasma concentrations. The term "selective spinal analgesia" was suggested since there were no changes in sympathetic or motor functions (18).

Wide-spread clinical use of spinal, i.e. Intrathecal and epidural, opioids followed, but much of the necessary pharmacokinetic and pharmacodynamic knowledge was lacking in the beginning $(11,19)$. 
Preclinical and in vitro experiments on spinal analgesia

Perception of noxious stimuli depends not only on peripheral stimulation and transmission but also on modulation occurring in the spinal cord and in the brain. Noxious stimuli are transmitted to the central nervous system by fine myelinated A-delta fibres and non-myelinated C-fibres. Cells in the spinal cord are excited by these stimuli but they can also be facilitated or inhibited by other peripheral nerve fibres carrying information about innocuous events. Descending control systems originating in the brain modulate the excitability of the cells transmitting noxious information $(103,118)$.

Central terminals of the unmyelinated afferents are located in the marginal zone (Rexed lamina I) and substantia gelatinosa (laminae II and III) of the dorsal horn. The larger diameter fibre terminals are found mainly in lamina IV (59).

\section{Neurotransmitter of noxious stimuli}

The excitatory neurotransmitters responsible for nociceptive transmission in the spinal cord have not been clearly identified. Many data point to substance $P$, a peptide containing 11 amino acids, as the transmitter. It is found in the dorsal root cell bodies from which the A-delta and C-fibres originate, and in the central terminals of small myelinated and unmyelinated fibres $(42,43)$. Substance $P$ is released into CSF in vivo by high intensity electrical stimulation of peripheral nerves in animals, and this release can be inhibited by intrathecal morphine $(114,117)$. Intrathecal administration of capsaicine, a homovanillic acid derivative, depletes dorsal horn substance $P$ in animals, and this causes an insensitivity to noxious thermal stimuli (113). It seems that substance $P$ has a dual action on nociception. Small doses cause analgesia while hyperalgesia occurs when higher doses are given (29).

\section{Pain inhibiting systems}

Several systems capable of inhibiting pain transmission on the spinal level have been described. These include an opioid system (110), a noradrenergic system, a serotoninergic system (111), a gamma-aminobutyric acid (GABA)-ergic system (112) and a cholinergic system (119). Most of these systems seem to be complementary and additive (112). Tolerance exists within the systems but there is probably no cross-tolerance between them $(50,114,116)$.

The endogenous opioid system has thus far been found to have members deriving from three precursors; the endorphins from pro-opiomelanocortin (68), the enkephalins from pro-enkephalin A (36) and dynorphin related peptides from proenkephalin B (52). 
All three peptide systems may have to be considered in the processing and modulation of nociception at different levels of the central nervous system. Enkephalin containing neurons are found at every level of the neuraxis, from the cortex to the spinal cord. At the spinal cord level, enkephalin terminals form a dense network in laminae I-IIb and $V$ of the dorsal horn (27). Neuronal cell bodies containing $\beta$-endorphin are relatively few, but can be found in limbic structures and the periaqueductal grey matter in the brain. The dynorphin terminals form a striato-nigral pathway, and they are also present in the hypothalamus, in certain other brain nuclei and in spinal interneurons $(65,102,106)$.

The opioid receptors are not a homogenous population. Several different subgroups have been demonstrated by binding studies with different opioid agonists. These include the mu, kappa, delta, epsilon and possibly sigma receptors $(15,49,108)$. The opioid peptides differ with regard to their affinity for the different receptor subtypes. Enkephalins have a high affinity for both delta and mu receptors, $\beta$-endorphin is non-selective, and dynorphin shows selectivity for kappa receptors (109).

Analgesia has generally been viewed as mediated through mu receptors $(2,54)$ but both delta and kappa receptors may be involved $(15,30)$.

\section{Mode of action of spinal opioids}

Based on iontophoretic application of opioids and autoradiographic studies, spinal opioids are considered to bind to opioid receptors in the spinal cord grey matter and thus probably inhibit primary afferent nociceptive transmission both pre-and postsynaptically $(26,31)$.

As the opioid peptides, different opiold drugs have different receptor affinity profiles, both with respect to receptor subtype and degree of receptor affinity (61). The significance of this, and the relationship between spinal opioid administration and the endogenous opioid peptides, remain to be determined, however.

\section{PHARMACODYNAMICS OF SPINAL OPIOIDS}

Spinal opiods have been used to relieve postoperative, posttraumatic, obstetric and chronic pain. Numerous studies have been published concerning this since 1979. A dose response relationship between epidural morphine and the efficacy of postoperative pain relief has been confirmed in double-blind studies $(62,69)$. Postoperative pain following epidural morphine has been re- 
ported to be less severe and of shorter duration than after systemic opioids $(38,51,57,78,86)$, while pethidine administered epidurally is as effective, or more effective, as parenteral pethidine postoperatively $(13,40,72)$. In patients with pain associated with cancer, a variable response to epidural morphine has been reported. Deep somatic pain is relieved more effectively than neurogenic pain and cutaneous pain (1).

Epidural morphine and pethidine have often been unable to relieve labour pain, while intrathecal morphine has been reported to relieve pain in the first stage of labour but only incompletely in the second stage $(3,7,45,47$, $74,89,94)$. The low efficacy of epldural morphine and pethidine in labour pain is probably influenced by reduced drug availability to the subarachnoid space in pregnancy because of rapid absorption to the blood via the enlarged epidural venous plexa $(20,48)$.

With spinal administration, different opiolds have different pharmacodynamic properties. The onset of pain relief is faster for fentanyl and pethidine than for morphine after epidural administration $(9,13,38,40,85)$, whereas the duration of analgesia is longer for epidural morphine than for fentanyl and pethidine $(9,13,33,38,40,77,85,100)$.

\section{Adverse effects}

Respiratory depression was recognized early, both after intrathecal $(32,60)$ and epidural morphine $(6,17,81)$. Early respiratory depression appearing within an hour following epidural administration of the opioid is believed to correlate to the plasma concentrations of the opioids $(14,20)$ and may be seen with any opioid given in sufficient dose. Reported cases of respiratory depression following epidural pethidine have all been of the early type $(37,88,115)$.

Late respiratory depression appearing up to 12 hours after injection has been reported following both intrathecal and epidural morphine $(6,17,32,37,60,81)$.

In a series of studies in healthy volunteers Bromage and co-workers $(10,12,14)$ have demonstrated that Iumbar epidural morphine spreads rostrally as judged from segmental spread of hypalgesia to pin scratch and ice. In parallel to the rostral spread was an increasing respiratory depression evidenced by changes in the carbon dioxide $\left(\mathrm{CO}_{2}\right)$ response curve. Onset of trigeminal analgesia and peak respiratory depression coincided 6-10 hours after injection. Marked respiratory depression was still present 22 hours after injection of lumbar epidural morphine. A dose-dependent long-lasting depression of ventilatory drive in response to $\mathrm{CO}_{2}$ from lumbar epidural morphine has been reported by Rawal and Wattwil ( 80 ). 
Respiratory depression following intrathecal morphine has a similar time delay $(32,60)$.

Epidural fentanyl does not cause respiratory depression in volunteers (56) and there have been no reports on clinical late respiratory depression following epidural administration of lipophilic opioids such as pethidine and fentanyl.

Old age, respiratory disease, lack of tolerance to opioids, concomitant use of parenteral opioids, thoracic administration and high doses of spinal morphine have all been suggested as risk factors for late respiratory depression following spinal opioids $(20,37,80)$.

If these factors are taken into consideration, the incidence of respiratory depression can be kept at a minimum $(20,37)$. Nevertheless, patients receiving spinal morphine should be observed several hours after the last injection $(21,80)$.

Naloxone-reversible relaxation of the detrusor and increased bladder capacity can lead to urinary retention after epidural morphine $(82,103)$. Urinary retention does not seem to be a problem with long-term use in patients with cancer pain $(33,121)$.

Other adverse effects described after spinal opioids include nausea, vomiting and itching (20). However, few comparative data are avallable as to the relative incidence of the adverse effects elicited by the different opioids.

\section{PHARMACOKINETICS OF SPINAL OPIOIDS}

The different times of onset and duration of analgesia as well as sideeffects have been tentatively linked to the physicochemical characteristics of the drugs $(101,115)$. All opioids are ionized primarily at a physiological $\mathrm{pH}$, making the molecules water soluble. However, the lipophilicity of the unionized fraction of the drugs differs. Morphine is the least lipophilic of the opioid drugs in clinical use, with an octanol-water partition coefficient of 1.42 at $\mathrm{pH} 7.4$, whereas pethidine and fentanyl have partition coefficients of 38.8 and 813 , respectively (53). The newer 4-anilinopiperidine analogues (e.g. alfentanil, sufentanil, lofentanil) are also highly lipophilic (64).

Experiments by Herz and Teschemacher revealed that onset time and duration of action of systemically administered opioids correlated with their lipid partition coefficients (41). It was, in analogy with this, hypothesized $(20,115)$ that spinally administered morphine, due to its relative hydrophilicity, passed the dura and/or penetrated to the receptor sites in the spinal cord 
slowly, while the other opioids penetrated biological membranes faster and, thus, had more rapid access to the receptor sites. This hypothesis would explain the observed differences in onset times.

The observed differences in duration of action would conversely be explained by the potential differences in efflux from spinal cord and CSF due to the different lipophilicities.

However, in vitro experiments have suggested that the molecular weight, and not the lipophilicity of an opioid, determines the rate of absorption across the dura (67). Since morphine and pethidine have about the same molecular weight, the absorption according to this hypothesis should be equally fast.

In recent years studies concerning the kinetics of spinal opioids $(16,33,39$, $55,69-71,77,91,92,105)$ have demonstrated that analgesia occurs in the presence of very low or undetectable plasma drug concentrations, supporting a spinal opioid action. When reviewing studies concerning the kinetics of spinal opioids one has to realize that the different studies are not necessarily comparable. Different doses, volumes, sites of administration, and CSE and plasma sampling spots and times all influence the results.

The sensitivity and specificity of the assay method are also factors of importance. For example, the radio immunoassay (RIA) for morphine used in some studies $(16,55,58)$ may codetermine inactive morphine-glucuronide (95). Since morphine-glucuronide levels can be higher than unchanged morphine levels at time intervals of 1 hour after systemic drug administration, the RIA may cause overestimation of morphine plasma concentrations (95).

When performing the pharmacokinetic analysis, the accuracy of the assay, the amount of data, and the method of calculation of the kinetic parameters influence the results.

The application of pharmacokinetic parameters such as "half-life" and "clearance" to the data from lumbar CSF sampling must also be interpreted with caution.

Clearance is traditionally a physiological parameter measuring the ability of the eliminating organs, usually the kidneys and the liver, to remove a drug (84). The clearance values obtained from the drug concentrations measured in lumbar CSF, however, do not reflect clearance through eliminating organs but rather clearance from the sampling spot.

The half-lives in CSF obtained from similar calculations also have to be interpreted with respect to the fact that they do not necessarily reflect what happens in the CSF compartment as a whole.

The time to reach maximal concentration in plasma ( $t_{\max }$ ) is generally longer after intrathecal administration than after epidural administration. (Pharmacokinetic data are given in Table 1.)

106 


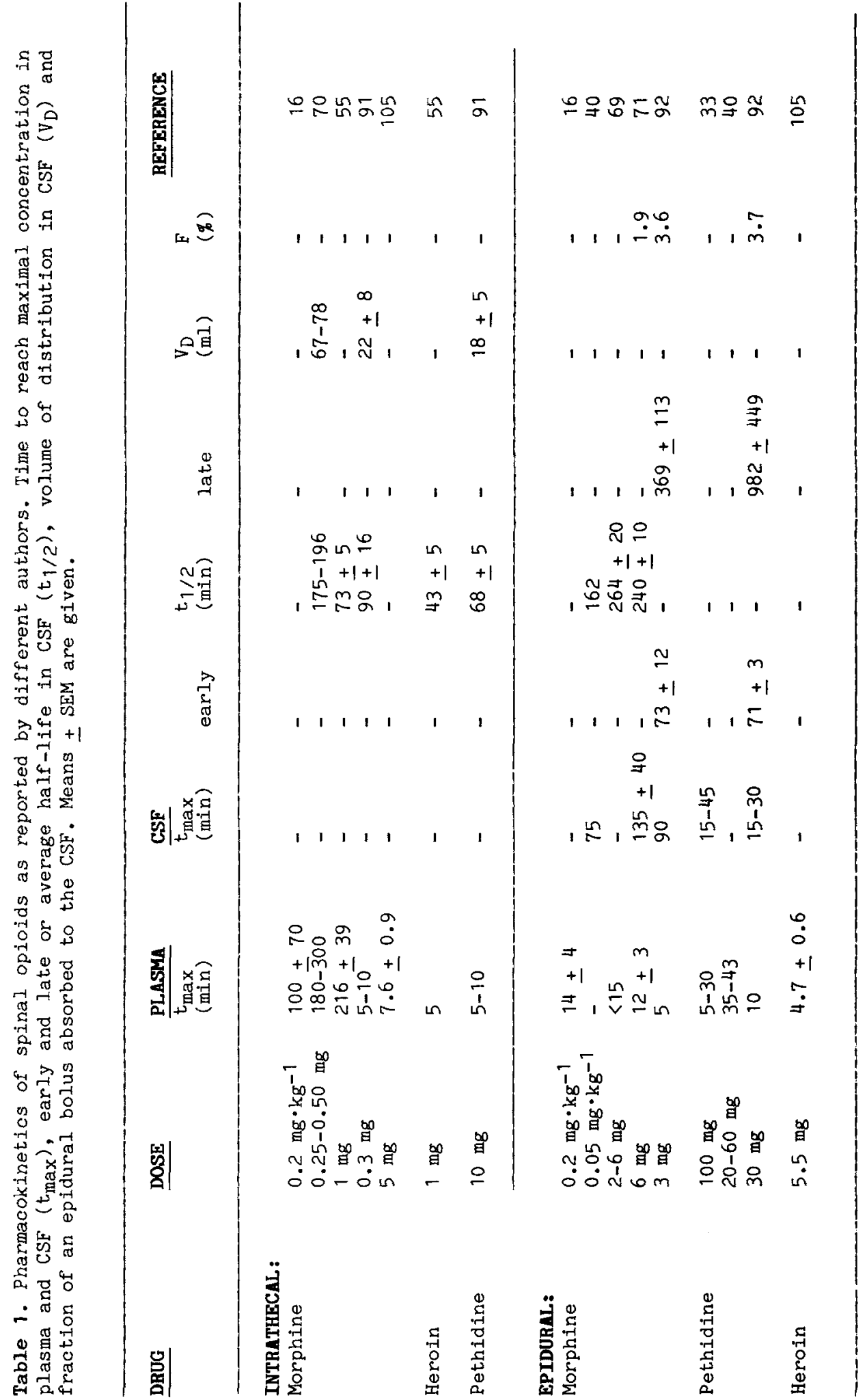


The CSF concentration time curve following intrathecal morphine displays a rapid fall during the first 15 minutes, followed by a slower fall during the next 4 to 6 hours $(55,70,91)$.

The same patter is seen following intrathecal heroin (55) and pethidine (91), but the elimination from CSF is faster. Six hours after injection, 1.6\% of the morphine dose and $0.4 \%$ of the pethidine dose remain in the initial volume of distribution in CSF (91).

The plasma concentration time curves following epidural administration usually resemble those after intramuscular administration. Plasma morphine concentrations occur significantly earlier after epidural heroin (diamorphine hydrochloride) than after epidural morphine (105).

The absorption of epidural morphine across the dura is relatively slow, and maximal CSF concentrations are seen 75 to 135 minutes after injection $(40,71,92)$. Absorption half-life across the dura is 22 minutes (92). Pethidine, on the other hand, crosses the dura faster, with an absorption halflife of 7.6 minutes (92). Maximal CSF concentrations are seen 15 to 45 minutes after injection $(33,92)$. Less than $4 \%$ of an epidural dose of morphine $(71,92)$ and pethidine (92) crosses the dura, but since the volumes of distribution in the subarachnoid space are much smaller than the volume of distribution in the whole body $(70,91)$, the CSF concentrations are several times greater than those in plasma as early as five minutes after injection $(33,69,70,91,92)$.

The CSF concentration time curves of both morphine and pethidine display a biphasic fall after the initial rise due to absorption from the epidural space. The half-lives of these falls are 73 and 369 minutes for morphine, and 71 and 982 minutes for pethidine, respectively (92). This means that a larger fraction of the morphine in the subarachnoid space stays in the CSF as compared to pethidine (92). Pethidine, on the other hand, seems to be transported more rapidly to a deep compartment in the subarachnoid space (e.g. nervous tissue). No significant differences in kinetics were seen when morphine was administered epidurally in 1 or $10 \mathrm{ml}$ (92). A striking feature in most studies is the large interindividual difference in kinetics.

\section{Distribution of drugs administered epidurally or intrathecally}

Several factors influence the distribution in the subarachnoid space of a drug injected intrathecally. Age, intraabdominal and intrathoracic pressures, site of injection, $\mathrm{pH}$ of the CSF, specific gravity, $\mathrm{pKa}$ and volume of the bolus and speed of injection all affect the distribution, as does the body position of the patient $(8,82)$. When the drug is administered epidurally the description of the distribution is further complicated. The absorption of the drug occurs to the blood through the epidural venous plexa and possibly 
through the posterior radicular artery leading directly to the spinal cord, but also to the subarachnoid space across the dura (20).

The opioid drugs are not evenly distributed in the spinal CSF, as indicated by a study where CSF was sampled at a cervical level following lumbar epidural administration of morphine in cancer patients (34). Both morphine and pethidine distribute initially in the subarachnoid space in a volume of about $20 \mathrm{ml}$ after intrathecal administration (91). This initial distribution is probably due mostly to diffusion in the CSF, since the initial volume of distribution was about the same for morphine and pethidine despite their different lipophilicities. The total volume of CSF is about $150 \mathrm{ml}$ with $25-75$ $\mathrm{ml}$ in the spinal canal $(8,82)$. Both drugs are thus rapidly distributed in a large fraction of lumbar CSF.

Site of injection

In a clinical setting, spinal opioids are often administered at the lumbar level (20). The lumbar epidural space is technically easier to reach than the thoracic epidural space and the consequenses of a potential dural puncture are more serious when a thoracic approach is used. The level of injection may not be crucial for the effect when epidural opioids are used, as indicated by the results of studies where lumbar epidural morphine and pethidine were capable of relieving post-thoracotomy pain $(69,83)$.

\section{RELATIONSHIP BETHEEN PHARMACOKINETICS AND PHARMACODYNAMTCS}

The reported onset of analgesia following epidural administration of morphine is 20 minutes and maximal pain relief is achieved 40-90 minutes after injection $(9,38,62,85)$. Onset of analgesia after epidural pethidine is faster, between 5 and $20 \mathrm{~min}(13,33,40,72,85)$.

This is closely parallelled by the different absorption half-lives across the dura of epidural morphine and pethidine $(33,69,92)$.

The reported duration of action is longer for epidural morphine than for epidural pethidine $(9,13,33,38,40,72,77,85,100)$, and this is reflected by a more rapid disappearance of pethidine from lumbar CSF (92).

The half-life of the late phase of pethidine elimination from CSF, between 12 and 24 hours after injection, tends to be longer than that of morphine. This probably reflects a slow release of the lipophilic opioid from nervous tissue 
in the subarachnoid space. Evidently the amount of pethidine present at that time is too low to cause reliable analgesia.

Measurable CSF concentrations of morphine and pethidine are still present in lumbar CSF 24 hours after epidural injection of a $3 \mathrm{mg}$ morphine and a $30 \mathrm{mg}$ pethidine bolus, respectively (92). This indicates that once in the subarachnoid space, pethidine is rapidly transported to a deep compartment, which probably consists of nervous tissue, while a large fraction of morphine is still present in the CSF several hours after injection. Thus, epidural morphine passes siowly from the epidural space to the subarachnoid space, but it also seems to leave the CSF compartment slowly.

This is interesting with respect to the duration of analgesia following spinal administration of opioids with different lipophilicities and also with respect to the appearance of supraspinal adverse effects such as late respiratory depression.

The cephalad bulk flow of CSF has been studied using radionuclides (24) and metrizamide, a water soluble contrast medium (25). These reach the basal cisterns within 30 minutes after Iumbar intrathecal administration. Several animal experiments $(35,39,73)$ have demonstrated a rostral transport of morphine, but no such transport, or else to a lesser extent, of pethidine and methadone. Morphine is, due to its hydrophilicity and slow elimination from CSF, more prone to be transported rostrally than lipophilic opioids.

Pethidine has local anesthetic properties in high concentrations (107). Presumably because of this, large doses of intrathecal pethidine $(1 \mathrm{mg} \cdot \mathrm{kg}-1$ ) can be used as the sole anaesthetic agent for short lower abdominal, perineal and lower limb surgery $(22,28,66)$. A profound sensory and motor block is produced which lasts about 1.5 hours, and long-lasting postoperative analgesia has been reported. Assuming linear kinetics, the results of the kinetic study following intrathecal pethidine by Sjöström et al. (91) indicate that high CSF pethidine concentrations are necessary for a motor block -about $0.2-2.5$ $\mathrm{mg} \cdot \mathrm{ml}^{-1}$. These concentrations are not likely to occur after epidural administration of pethidine. Since only about $4 \%$ of an epidural bolus of pethidine is absorbed to the subarachnoid space, the administration of $70 \mathrm{mg}$ of pethidine intrathecally can be compared to the administration of $1.5-2$ (sic!) epidurally in terms of subarachnoid space availability. 
The analgetic effect of epidural morphine seems to reach a plateau quickly, as evidenced by a study where $2 \mathrm{mg}$ doses of epidural morphine were more effective than 0.5 or $1 \mathrm{mg}$ doses, but equally effective as 4 and $8 \mathrm{mg}$ doses (62). Some authors claim that epidural morphine doses of $10 \mathrm{mg}$ or $0.1 \mathrm{mg} \cdot \mathrm{kg}^{-1}$ and pethidine doses of $100 \mathrm{mg}$ are necessary to obtain an adequate level of analgesia after upper abdominal, thoracic or lower limb surgery $(9,33,57)$ while others report good postoperative analgesia following $2-4 \mathrm{mg}$ doses of epidural morphine, with mean durations ranging from 7 to 16 hours $(62,70,77)$ and 10-60 mg doses of epidural pethidine with durations from 3 to 7 hours or more $(13,18,72,100)$.

The existing differing dose recommendations are probably due to the different situations with different causes of pain and different patient categories with different ages in which spinal opioids have been used. Analgesic consumption postoperatively has been shown to correlate to the activity of the endogenous opioid system $(76,97)$ but this activity, and its modification by different kinds of stress, anaesthesia and other medication, is largely unknown.

Another possible explanation for the differing dose recommendations and durations of analgesia following spinal opioids may be that different authors have differing definitions of pain relief (21). The ability to move around freely in bed, to ambulate and to take deep breaths and cough without or with only minor pain is or is not included in the definition of pain relief.

A further explanation for the different dose recommendations and durations is the widely varying CSF kinetics.

The equianalgesic dose relationships between drugs depend not only on the analgetic effect of the drug, but also on the duration of analgesia. The equianalgesic dose relationship between systemic morphine and pethidine is known to be 1 to 10. In a study by Sjöström et al. this was investigated for epidural morphine and pethidine using patient-controlled analgesia (PCA) (93). Self-administration of epidural bolus increments of morphine $1 \mathrm{mg}$ or pethidine $20 \mathrm{mg}$ was started postoperatively after major abdominal surgery.

Pain relief from epidural PCA with morphine and pethidine was excellent in all but two patients in the morphine group. PCA lasted for a mean period of 16 hours. The average consumption of morphine was $0.52 \mathrm{mg} \cdot \mathrm{h}^{-1}$ (range 0.15 $1.04, n=15$ ) and of pethidine it was $18.0 \mathrm{mg} \cdot \mathrm{h}^{-1}$ (range $5.8-35.4, \mathrm{n}=15$ ). The consumption thus varied five- to six-fold in both groups. The equianalgesic dose relationship between epidural morphine and pethidine could be calculated 
to be 1:35. On a time continuum, morphine consumption was more irregular than pethidine consumption. Pain assessment on the VAS scale did not differ between the groups. No cases of respiratory depression were seen. Adverse effects reported in a postoperative questionnaire were slight. Twenty-nine of the thirty patients who used epidural PCA rated the pain relief as "very efficient". Plasma concentrations of both morphine and pethidine were low during epidural PCA as compared with intravenous PCA $(23,98)$.

The difference in equianalgesic dose relationship between systemic and epidural opiolds reflects the closeness of the site of administration to the opiold receptors in the spinal cord, and differences in CSF kinetics and in opioid receptor affinities (61).

The five to six fold variation in morphine and pethidine consumption during epidural PCA may partly be accounted for by the pharmacokinetic properties of the drugs. However, the variability further emphasizes the individual difference in pain perception.

By using kinetic parameters from the kinetic study by Sjöström et al. (92) and drug utilization data from the PCA study (93), the lumbar CSF concentrations of morphine and pethidine during epidural PCA can be simulated (figure 1). These simulated CSF concentrations turn out to be very high. The CSF concentrations that are calculated for the time of supplementary analgesia during $\mathrm{PCA}$ are around $300 \mathrm{ng} \cdot \mathrm{ml}^{-1}$ for morphine and 10.000 to $13.000 \mathrm{ng} \cdot \mathrm{ml}^{-1}$ for pethidine. These concentrations are far higher than those reported after single doses $(58,92)$.

This discrepancy may indicate real differences in single dose and multiple dose kinetics. The spinal kinetics of a drug injected intrathecally or epidurally is, by and large, determined by the concentration-gradients between the epidural space, the CSF, the spinal cord and the blood. Only a small fraction, about 4\%, of an epidural single bolus dose of morphine or pethidine is absorbed to the subarachnoid space (92). The main fraction of the bolus dose is rapidly absorbed to the blood. Due to the large differences in the voiumes of distribution $(23,70,91,98)$ the concentrations in CSF exceed those in plasma many times over. When multiple doses of epidural opioids are administered, the resulting concentration gradients favour the systemic absorbtion of a second epidural dose. According to this hypothesis, as CSF concentrations gradually rise during repetitive doses, a successively smaller fraction of each dose is then absorbed to the subarachnoid space.

The large inter-individual variation makes it impossible to recommend a standard dose of epidural morphine or pethidine for analgesia of predictable duration and with a minimum of adverse effects. Patient-controlled analgesia 

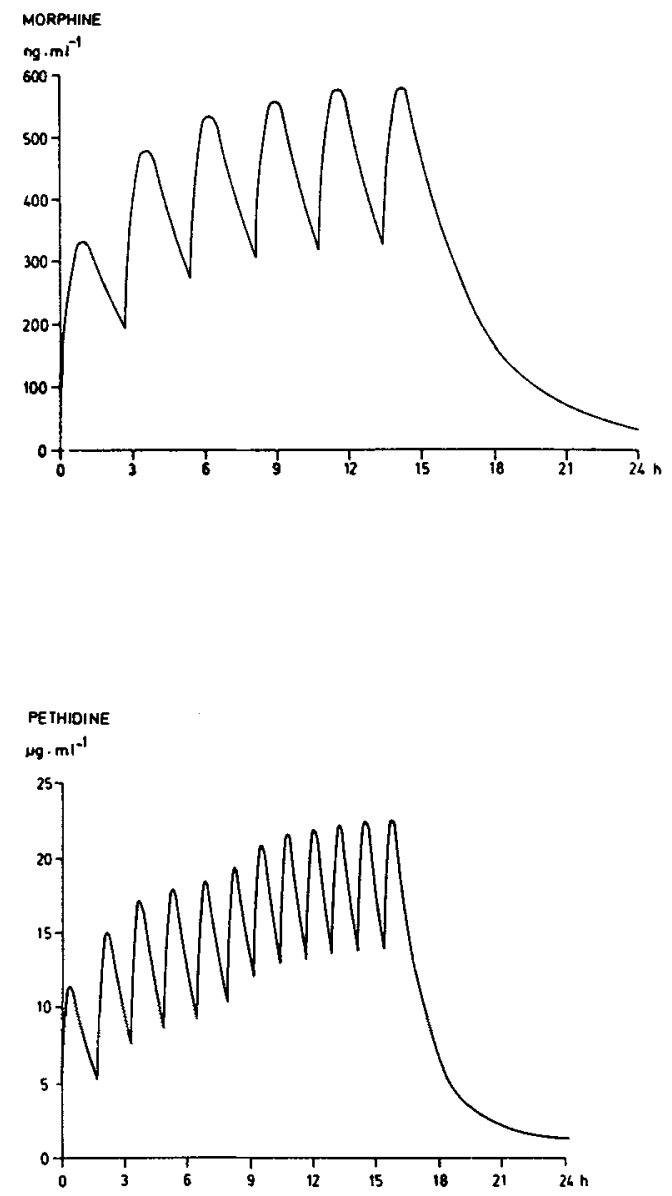

Fig. 1. Computer simulated mean CSF morphine and pethidine concentrations during epidural PCA using reported pharmacokinetic data (92) and drug utilization data (93).

via the epidural route thus provides an alternative way to give an individualized pain therapy.

The volume of an epidural bolus is probably not a factor of major importance, which is indicated by the lack of significant differences in kinetics between epidural morphine administered in 1 or $10 \mathrm{ml}$ (92). The increased area of the dura exposed to the drug in the large volume group is evidently balanced, to a large extent, by the increased difference in concentrations across the dura in the small volume group. It has been suggested that increasing the volume 
of a morphine bolus increases the duration of analgesia (46), but this remains to be shown.

\section{DOSE CONSIDERATIONS - INTRATHECAL MORPHINE AND PETHIDINE}

Intrathecal morphine has been used in widely varying doses, from less than $0.1 \mathrm{mg}$ to $20 \mathrm{mg}(87,96)$. Small doses of $0.25-0.5 \mathrm{mg}$ alone or in combination with local anaesthetics for spinal anaesthesia have been reported to give pain relief for $12-24 \mathrm{~h}$ or more $(5,70)$.

The most commonly used doses of epidural morphine are in the range of 3 to 10 mg. A CSF availability of $3.6 \%$ of epidural morphine (92) means that about $0.2 \mathrm{mg}$ and $0.4 \mathrm{mg}$ of epidural boluses of 5 and $10 \mathrm{mg}$, respectively reach the subarachnoid space.

The large inter-individual variation in morphine CSF kinetics may explain some of the reported individual differences in the duration of analgesia after intrathecal morphine. It also makes it very difficult, or even impossible, to suggest a standard dose which produces a long duration of pain relief to the individual patient without exposing the patient to the risk of an overdose with potential adverse effects.

A certain variability of the clinical effect, due to the inter-individual differences in kinetics, can also be expected after intrathecal pethidine.

\section{THE "IDEAL" SPINAL OPIOTD}

A lipophilic opioid with a strong affinity for the opioid receptors might theoretically be an "ideal" opioid for epidural use. A rapid onset of pain relief due to rapid absorption through the dura to the spinal cord, a long duration of action because of slow removal of the last small fraction from the subarachnoid space, and a low risk of rostral transport because of rapid removal from the CSF, are advantages which would be combined.

A potential problem with an opioid with a strong affinity for the opioid receptors is that it may be difficult or even impossible to reverse the opioid effects with naloxone. This has been demonstrated for lofentanil, one of the new anilinopiperidines (120). Intrathecal sufentanil and alfentanil, other agents from this class, have been shown to be at least as effective as morphine in rat studies, but with shorter durations of action (120). There is also a possibility that increased lipophilicity increases systemic redistribution following spinal administration, which could counteract the positive effects of increased lipophilicity following spinal administration. 
The combination of small doses of opioids and local anesthetics, might prove to be an interesting future development.

\section{REFERENCES}

1. Arnér, S. \& Arnér, B.: Differential effects of epidural morphine in the treatment of cancer-related pain. Acta Anaesth Scand 29: 32-36, 1985.

2. Audigier, Y., Mazarguil, H., Gout, R \& Cros, J.: Structure-activity relationships of enkephalin analogs at opiate and enkephalin receptors: Correlation with analgesia. Eur J Pharmacol 63: 35-46, 1980.

3. Baraka, A., Noueihid, R. \& Hajj, S.: Intrathecal injection of morphine for obstetric analgesia. Anesthesiology 54: 136-140, 1981.

4. Behar, M., Olshwang, D., Magora, F. \& Davidson, J.T.: Epidural morphine in treatment of pain. Lancet I: 527-529, 1979.

5. Bengtsson, M., Löfström, J.B. \& Merits, H.: Postoperative pain relief with intrathecal morphine after major hip surgery. Regional Anesthesia 8: $140-143,1983$.

6. Boas, R.A.: Hazards of epidural morphine. Anaesth Intensive Care 8: 377$378,1980$.

7. Booker, P.D., Wilkes, R.G., Bryson, T.H.L. \& Beddard, J.: Obstetric pain relief using epidural morphine. Anaesthesia 35: 377-379, 1980.

8. Bridenbaugh, P.0. \& Kennedy, W.F.: Spinal, subarachnoid neural blockade. In Cousins MJ, Bridenbaugh PO (Eds ): Neural blockade in clinical anesthesia and management of pain, Lippincott Company, Philadelphia, 1980, pp. 146-175.

9. Bromage, P.R., Camporesi, E. \& Chestnut, D.: Epidural narcotics for postoperative analgesia. Anesth Analg 59: 473-480, 1980.

10. Bromage, P.R., Camporesi, E. \& Leslie, J.: Epidural narcotics in volunteers: Sensitivity to pain and to carbon dioxide. Pain 9: 145-160, 1980.

11. Bromage, P.R.: The price of intraspinal narcotic analgesia: Basic constraints (Editorial). Anesth Analg 60: 461-463, 1981.

12. Bromage, P.R., Camporesi, E.M., Durant, P.A.C. \& Nielssen, C.H.: Rostral spread of epidural morphine. Anesthesiology 56: 431-436, 1982.

13. Brownridge, P. \& Frewin, D.B.: A comparative study of techniques of postoperative analgesia following caesarean section and lower abdominal surgery. Anesth Intensive Care 13: 123-130, 1985.

14. Camporesi, E.M., Nielsen, C.H., Bromage, P.R. \& Durant, P.A.C.: Ventilatory $\mathrm{CO}_{2}$ sensitivity after intravenous and epidural morphine in volunteers. Anesth Analg 62: 633-640, 1983.

15. Chang, K.J. \& Cuatrecasas, P.: Heterogeneity and properties of opiate receptors. Fed Proc 40: 2729-2734, 1981.

16. Chauvin, M., Samii, K., Schermann, J.M., Sandouk, P., Bourdon, R. \& Viars, P.: Plasma concentration of morphine after $i . m .$, extradural and intrathecal administration. Br J Anaesth 54: 843-847, 1982.

17. Christensen, V.: Respiratory depression after extradural morphine. Br J Anaesth 52: 841, 1980.

18. Cousins, M.J., Mather, L.E., Glynn, C.J., Wilson, P.R. \& Graham, J.R.: Selective spinal analgesia. Lancet I: 1141-1142, 1979.

19. Cousins, M.J., Glynn, C.J., Wilson, P.R., Mather, L.E. \& Graham, J.R.: Epidural morphine. Anaesth Intensive Care 8: 217-218, 1980.

20. Cousins, M.J. \& Mather, L.E.: Intrathecal and epidural administration of opioids. Anesthesiology 61: 276-310, 1984.

21. Cousins, M.J. \& Bridenbaugh, P.O.: Spinal opioids and pain relief in acute care. In: Cousins MJ, Phillips GD (eds): Acute pain management. Churchill Livingstone, New York, pp 151-185, 1986. 
22. Cozian, A., Pinaud, M., Lepage, J.Y., Lhoste, F \& Souron, R.: Effects of meperidine spinal anesthesia on hemodynamics, plasma catecholamines, angiotensin $I$, aldosterone, and histamine concentrations in elderly men. Anesthesiology 64: 815-819, 1986.

23. Dahlström, B., Tamsen, A., Paalzow, L. \& Hartvig, P.: Patient-controlled analgesic therapy, part IV: Pharmacokinetics and analgesic plasma concentrations of morphine. Clin Pharmacokinet 7: 266-279, 1982.

24. Di Chiro, G.: Movement of the cerebrospinal fluid in human beings. Nature 204: 290-291, 1964.

25. Drayer, B.P. \& Rosenbaum, A.E.: Studies on the third circulation. Amipaque CT cisternography and ventriculography. J Neurosurg 48: 946-956, 1978.

26. Duggan, A.W., Hall, J.G. \& Heally, P.M.: Suppression of transmission of nociceptive impulses by morphine: selective effects of morphine administered in the region of the substantia gelatinosa. Br J Pharmacol 61: 6576,1977 .

27. Elde, R., Hökfelt, T., Johansson, 0. \& Terenius, L.: Immunohistochemical studies using antibodies to leucine-enkephalin: initial observations on the nervous system of the rat. Neuroscience 1: 349-351, 1976.

28. Famewo, C.E. \& Naguib, M.: Spinal anaesthesia with meperidine as the sole agent. Can Anaesth Soc J 32: 533-537, 1985.

29. Frederickson, R.C.A., Burgis, V., Harrel, C.E. \& Edwards, J.D.: Dual actions of substance $P$ on nociception: Possible role of endogenous opioids. Science 199: 1359-1362, 1978.

30. Frederickson, R.C.A., Smithwick, E.L., Shuman, R. \& Bemis, K.G.: Metkephamid, a systemically active analog of methionine enkephalin with potent opioid delta-receptor activity. Science $211: 603-605,1981$.

31. Game, C.J.A. \& Lodge, D.: The pharmacology of the inhibition of dorsal horn neurones by impulses in myelinated cutaneous afferents in the cat. Exp Brain Res 23: 75-84, 1975.

32. Glynn, C.J., Mather, L.E., Cousins, M.J., Wilson, P.R. \& Graham, J.R.: Spinal narcotics and respiratory depression. Lancet II: 356-357, 1979.

33. Glynn, C.J., Mather, L.E., Cousins, M.J., Graham, J.R. \& Wilson, P.R.: Peridural meperidine in humans: Analgetic response, pharmacokinetics and transmission into CSF. Anesthesiology 55: 520-526, 1981.

34. Gourlay, G.K., Cherry, D.A. \& Cousins, M.J.: Cephalad migration of morphine in CSF following lumbar epidural administration in patients with cancer pain. Pain 23: 317-326, 1985.

35. Gregory, M.A., Brock-Utne, J.G., Bux, S. \& Downing, J.W.: Morphine concentration in brain and spinal cord after subarachnoid morphine injection in baboons. Anesth Analg 64: 929-932, 1985.

36. Gubler, U., Seeburg, P., Hoffman, B.J., Gage, L.P. \& Udenfriend, S.: Molecular cloning establishes proenkephalin as precursor of enkephalincontaining peptides. Nature 295: 206-208, 1982.

37. Gustafsson, L.L., Schildt, B. \& Jacobsen, K.: Adverse effects of extradural and intrathecal opiates: Report of a nationwide survey in Sweden. Br J Anaesth 54: 479-486, 1982.

38. Gustafsson, L.L., Friberg-Nielssen, S., Garle, M., Mohall, A., Rane, A., Schlldt, B. \& Symreng, T.: Extradural and parenteral morphine: Kinetics and effects in postoperative pain. A controlled clinical study. $\mathrm{Br} J$ Anaesth 54: 1167-1178, 1982.

39. Gustafsson, L.L., Post, C., Edvardsen, B. \& Ramsay, C.H.: Distribution of morphine and meperidine after intrathecal administration in rat and mouse. Anesthesiology 63: 483-489, 1985.

40. Gustafsson, L.L., Johannisson, J. \& Garle, M.: Extradural and parenteral pethidine. Eur J Clin Pharmacol 29: 529-534, 1986.

41. Herz, A. \& Teschemacher, H.J.: Activities and sites of antinociceptive action of morphine-like analgesics and kinetics of distribution following intravenous, intracerebral and Intraventricular application. In: Harper NJ, Simmonds $A B$ (Eds): Advances in drug research 6, Academic Press, New York, 1971, pp 79-119. 
42. Hökfelt, T., Kellerth, J.0., Nilsson, G. \& Pernow, B.: Substance P: Localization in the central nervous system and in some primary sensory neurons. Science 190: 889-890, 1975.

43. Hökfelt, T., Ljungdahl, A., Elde, R., Nilsson, G. \& Terenius, L.: Immunohistochemical analysis of peptide pathways possibly related to pain and analgesia: Enkephalin and substance P. Proc Nat1 Acad Sci 74: 3081-3085, 1977.

44. Hughes, J., Smith, T.W., Kosterlitz, H.W., Fothergill, L.A., Morgan, L.A., Morgan, B.A. \& Morris, H.R.: Identification of two related pentapeptides from the brain with potent opiate agonist activity. Nature 258: 577-579, 1975.

45. Hughes, S.C., Abboud, T.K., Shnider, S.M., Stefani, S.J. \& Norton, M.: Maternal and neonatal effects of epidural morphine for labor. Anesth Analg 61: 190, 1982.

46. Husegaard, H.C., Joensen, F., Vestergaard Madsen, J., Möller, L.V., Rybro, L., Asmin Schurizek, B. \& Wernberg, M.: The influence of the volume of the solution on the effect of epidural morphine. Ugeskr Laeger $147: 873-876,1985$.

47. Husemeyer, R.P., O'Connor, M.C. \& Davenport, H.T.: Failure of epidural morphine to relieve pain in labour. Anaesthesia 35: 161-163, 1980.

48. Husemeyer, R.P., Cummings, A.J., Rosankievicz, J.R. \& Davenport, H.T.: A study of pethidine kinetics and analgesia in women in labour following intravenous, intramuscular and epidural administration. Br J Pharamacol 13: $171-176,1982$.

49. Iwamoto, E.T. \& Martin, W.R.: Multiple opioid receptors. Med Res Rev 1: $411-440,1981$.

50. Johnson, S.M. \& Duggan, A.W.: Tolerance and dependence of dorsal horn neurones of the cat: The role of the oplate receptors of the substantia gelatinosa. Neuropharmacology 20: 1033-1038, 1981.

51. Jörgensen, B.C., Andersen, H.B. \& Engquist, A.: Influence of epidural morphine on postopertive pain, endocrine-metabolic, and renal responses to surgery. A controlled study. Acta Anaesthiol Scand 26: 63-68, 1982.

52. Kakidani, H., Furutani, Y., Takahashi, H., Noda, M., Morimoto, Y., Hirose, T., Asai, M., Inayama, S., Nakanashi, H. \& Numa, S.: Cloning and sequence analysis of cDNA for porcine $\beta$-neo-endorphin/dynorphin precursor. Nature 298: 245-249, 1982.

53. Kaufman, J.J., Semo, N.M. \& Koski, W.S.: Microelectrometric measurement of the pKa's and partition and drug distribution coefficients of narcotics and narcotic antagonists and their $\mathrm{pH}$ temperature dependence. $\mathrm{J}$ Med Chem 18: 647-655, 1975.

54. Kosterlitz, H.W., Lord, J.A.H., Paterson, S.J. \& Waterfield, A.A.: Effects of changes in the structure of enkephalins and of narcotic analgesic drugs on their interactions with mu- and delta-receptors. $\mathrm{Br} J$ Pharmacol 68: 333-342, 1980.

55. Kotob, H.I.M., Hand, C.W., Moore, R.A., Evans, P.J.D., Wells, J., Rubin, A.P. \& McQuay, H.J.: Intrathecal morphine and heroin in humans: Six-hour drug levels in spinal fluid and plasma. Anesth Analg 65: 718-722, 1986.

56. Lam, A.M., Knill, R.J., Thompson, W.R., Clement, J.L., Varkey, G.P. \& Spoerel, W.E.: Epidural fentanyl does not cause delayed respiratory depression. Can Anaesth Soc J 30: S78-S79, 1983.

57. Lanz, E., Theiss, D., Riess, W. \& Sommer, U.: Epidural morphine for postoperative analgesia: a double blind study. Anesth Analg 61: 236-240, 1982.

58. Lazorthes, Y., Gouarderes, C., Verdie, J.C., Monsarrat, B., Bastide, R., Campan, L., Alwan, A. \& Cros, J.: Analgesie par injection intrathecale de morphine. Etude pharmacocinetique et application aux doleurs irreductibles. Neurochirurgie 26: 159-164, 1980.

59. Light, A.R. \& Perl, E.R.: Spinal termination of functionally identified primary afferent neurons with slowly conducting myelinated fibers. J Comp Neurol 186: 133-150, 1979. 
60. Liolos, A. \& Andersen, F.H.: Selective spinal analgesia. Lancet 2: 357, 1979.

61. Magnan, J., Paterson, S.J., Tavani, A. \& Kosterlitz, H.W.: The binding spectrum of narcotic analgesic drugs with different agonist and antagonist properties. Naunyn-Schmiedberg's Arch Pharmacol 319: 197-205, 1982.

62. Martin, B., Salbaing, J., Blaise, G., Tetrault, J.P. \& Tetrault, L.: Epidural morphine for postoperative pain relief: A dose-response curve. Anesthesiology 56: 423-426, 1982.

63. Martin, W.R.: Opioid antagonists. Pharmacol Rev 19: 463-521, 1967.

64. Mather, L.E.: Clinical pharmacokinetics of fentanyl and its newer derivatives. Clin Pharmacokin 8: 422-446, 1983.

65. Maysinger, D., Höllt, V., Seizinger, B.R., Mehraein, P., Pasi, A. \& Hertz, A.: Parallel distribution of immunoreactive alpha-neo-endorphin and dynorphin in rat and human tissue. Neuropeptides 2: 211-225, 1982.

66. Mircea, N., Constaninescu, C., Jianu, E., Busu, G., Ene, C., Daschievici, S., Nedelcu, A. \& Leoveanu, A.: L'anesthesie sous-arachnoidienne par la pethidine. Ann $\mathrm{Fr}$ Anesth Reanim 1: 167-171, 1982.

67. Moore, R.A., Bullingham, E.S., McQuay, H.J., Hand, C.W., Aspel, J.B., Allen, M.C. \& Thomas, D.: Dural permeability to narcotics: In vitro determination and application to extradural administration. $\mathrm{Br} J$ Anaesth 54: $1117-1128,1982$.

68. Nakanishi, S., Inoue, A., Kita, T., Nakamura, M., Chang, A.C.Y., Cohen, S.N. \& Numa, S.: Nucleotide sequence of cloned CDNA for bovine certicotropin-B-1ipotropin precursor. Nature 278: 423-427, 1979.

69. Nordberg, G., Hedner, T., Mellstrand, T. \& Dahlström, B.: Pharmacokinetic aspects of epidural morphine analgesia. Anesthesiology 58: 545-551, 1983.

70. Nordberg, G., Hedner, T., Mellstrand, T. \& Dahlström, B.: Pharmacokinetic aspects of intrathecal morphine analgesia. Anesthesiology 60: 448-454, 1984.

71. Nordberg, G., Hedner, T., Mellstrand, T. \& Borg, L.: Pharmacokinetics of epidural morphine in man. Eur J Clin Pharmacol 26: 233-237, 1984.

72. Payne, K.A.: Epidural versus intramuscular pethidine in postoperative pain relief. S Afr Med J 63: 196-200, 1983.

73. Payne, R. \& Inturrisi, C.E.: CSF distribution of morphine, methadone and sucrose after intrathecal injection. Life Sci 37: 1137-1144, 1985.

74. Perris, B.W.: Epidural pethidine in labour - a study of dose requirements. Anaesthesia 35: 380-382, 1980.

75. Pert, C.B. \& Snyder, S.H.: Opiate receptors: demonstrations in nervous tissue. Science 179: 1011-1014, 1973.

76. Puig, M., Laorden, M.L., Miralles, F.S. \& Olaso, M.J.: Endorphin levels in cerebrospinal fluid of patients with postoperative and chronic pain. Anesthesiology 57: 1-4, 1982.

77. Rawal, N., Sjöstrand, U.H. \& Dahlström, B.: Postoperative pain relief by epidural morphine. Anesth Analg 60: 726-731, 1981.

78. Rawal, N., Sjöstrand, U.H., Dahlström, B., Nydahl, P.A. \& Östelius, J.: Epidural morphine for postoperative pain relief: a comparative study with intramuscular narcotic and intercostal nerve block. Anesth Analg 61: 9398, 1982 .

79. Rawal, N., Möllefors, K., Axelsson, K., Lingårdh, G. \& Widman, B.: An experimental study of urodynamic effects of epidural morphine and of naloxone reversal. Anesth Analg 62: 641-647, 1983.

80. Rawal, N. \& Wattwil, M.: Respiratory depression following epidural morphine. An experimental and clinical study. Anesth Analg 63: 8-14, 1984.

81. Reiz, S. \& Westberg, M.: Side effects of epidural morphine. Lancet 2: 203-204, 1980.

82. Reynolds, F.J.M.: Spinal and epidural block. In Wylie WD, ChurchillDavidson HC (Eds): A practice of anaesthesia, LIoyd-Luke Ltd, London, 1984, pp 856-892.

83. Robinson, R.J.S., Brister, S., Jones, E. \& Quigly, M.: Epidural meperidine analgesia after cardiac surgery. Can Anaesth Soc J 33: 550-555, 1986. 
84. Rowland, M. \& Tozer, T.N.: Clinical pharmacokinetics: concepts and applications, Lea \& Febiger, Philadelphia, 1980, pp 48-63.

85. Rutter, D.V., Skewes, D.G. \& Morgan, M.: Extradural opioids for postoperative analgesia. A double-blind comparison of pethidine, fentanyl and morphine. Br J Anaesth 53: 915-920, 1981.

86. Rybro, L., Schurizek, B.A., Petersen, T.K. \& Wernberg, M.: Postoperative analgesia and lung function: a comparison of intramuscular with epidural morphine. Acta Anaesthiol Scand 26: 514-518, 1982.

87. Samii, K., Chauvin, M. \& Viars, P.: Postoperative spinal analgesia with morphine. $\mathrm{Br} \mathrm{J}$ Anaesthesia 53: 817-820, 1981.

88. Scott, D.B. \& McClure, J.: Selective epidural analgesia. Lancet 1: 1410$1411,1979$.

89. Scott, P.V., Bowen, F.E., Cartwright, P., Mohan Rao, B.C., Deeley, D., Wotherspoon, H.G. \& Sumrein, I.M.A.: Intrathecal morphine as sole analgesle during labour. Br Med $J$ 281: 351-353, 1980.

90. Simon, E.J., Hiller, J.M. \& Edelman, I.: Stereospecific binding of the potent narcotic analgesic $3 \mathrm{H}$-etorphine to rat brain homogenate. Proc Nat1 Acad Sc1 USA 70: 1947-1949, 1973.

91. Sjöström, S., Tamsen, A., Persson, P. \& Hartvig, P.: Pharmacokinetics of Intrathecal morphine and meperidine in humans. Anesthesiology (accepted for publication).

92. Sjöström, S., Hartvig, P., Persson, P. \& Tamsen, A.: Pharmacokinetics of epidural morphine and meperidine in humans. Anesthestology (accepted for publication).

93. Sjöström, S., Hartvig, P. \& Tamsen, A.: Patient-controlled analgesia with epidural morphine or pethidine. Br J Anaesth (accepted for publication).

94. Skjöldebrand, A., Garle, M., Gustafsson L.L., Johansson, H., Lunell, N.O. \& Rane, A.: Extradural pethdine with and without adrenaline during labour: wide variation in effect. Br J Anaesth 54: 415-420, 1982.

95. Stanski, D.R., Paalzow, L. \& Edlund, P.0.: Morphine pharmacokinetics: GLC assay versus radioimmunoassay. J Pharm Sci 71: 314-317, 1982.

96. Takasaki, M. \& Asano, M.: Intrathecal morphine combined with hyperbaric tetracaine. Anaesthesia 38: 76-77, 1983.

97. Tamsen, A., Sakurada, T., Wahlström, A., Terenius, L. \& Hartvig, P.: Postoperative demand for analgesics in relation to individual levels of endorphins and substance $P$ in cerebrosplnal fluid. Pain 13: 171-183, 1982.

98. Tamsen, A., Hartv1g, P., Fagerlund, C. \& Dahlström, B.: Patientcontrolled analgesic therapy II: Individual analgesic demand and analgesic plasma concentrations of pethidine in postoperative pain. Clin Pharmacokin 7: 164-175, 1982.

99. Terenius, L.: Stereospecific interaction between narcotic analgesic and a synaptic plasma membrane fraction from rat brain. Acta Pharmacol Toxicol 33: 377-384, 1974.

100. Torda, T.A. \& Pybus, D.A.: Comparison of four narcotic analgesics for extradural analgesia. Br J Anaesth 54: 291-295, 1982.

101. Tung, A.S. \& Yaksh, T.L.: The antinociceptive effects of epidural oplates in the cat: Studies on the pharmacologiy and the effects of lipophilicity in spinal analgesia. Pain 12: 343-356, 1982.

102. Vincent, S.R., Hökfelt, T., Christensen, I. \& Terenius, L.: Dynorphinimmunoreactive neurons in the central nervous system of the rat. Neurosci Lett 35: 185-190, 1982.

103. Wall, P.D.: The gate control theory of pain mechanisms. A re-examination and restatement. Brain 101: 1-18, 1978.

104. Wang, J.K., Nauss, L.E. \& Thomas, J.E.: Pain rellef by intrathecally applied morphine in man. Anesthesiology 50: 149-151, 1979.

105. Watson, J., Moore, A., Mc Quay, H., Teddy, P., Baldwin, D., Allen, M. \& Bullingham, R.: Plasma morphine concentrations and analgesic effects of lumbar extradural morphine and heroin. Anesth Analg 63: 629-634, 1984. 
106. Watson, S.J., Khachaturian, H., Akil, H., Coy, D. \& Goldstein, A.: Comparison of the distribution of dynorphin systems and enkephalin. systems in brain. Science 218: 1134-1136, 1982.

107. Way, E.L.: Studies on the local anesthetic properties of isonipecaine. J Am Pharm Assoc 35: 44-47, 1946.

108. Wister, M., Schulz, R. \& Herz, A.: The direction of opioid agonists towards mu, delta and kappa receptors in the vas deferens of the mouse and rat. Life Sci 27: 163-170, 1980.

109. Wister, M., Rubini, P. \& Schulz, R.: The preference of putative proenkephalins for different types of opiate receptors. Life Sci 29: 1219$1227,1981$.

110. Yaksh, T.L. \& Rudy, T.A.: Analgesia mediated by a direct spinal action of narcotics. Science 192: 1357-1358, 1976.

111. Yaksh, T.L.: Direct evidence that spinal serotonin and noradrenaline terminals mediate the spinal antinociceptive effects of morphine in the periaqueductal gray. Brain Res 160: 180-185, 1978.

112. Yaksh, T.L.: The synergistic interaction of three pharmacologically distinct spinal systems mediating antinociception: the intrathecal action of morphine serotonin and baclofen. Soc Neurosci (abstr) 4: 437, 1978.

113. Yaksh, T.L., Farb, D., Leeman, S. \& Jessel, T.: Intrathecal capsaicin depletes substance $P$ in the rat spinal cord and produces prolonged thermal analgesia. Science 206: 4811-483, 1979.

114. Yaksh, T.L., Jessel, T.M., Gamse, R., Mudge, A.W. \& Leeman, S.E.: Intrathecal morphine inhibits substance $\mathrm{p}$ release from mammalian spinal cord in vivo. Nature (Lond) 286: 155-156, 1980.

115. Yaksh, T.L.: Spinal opiate analgesia: Characteristics and principles of action. Pain 11: 293-346, 1981.

116. Yaksh, T.L. \& Reddy, S.V.R.: Studies on the analgetic effects of intrathecal opiates, adrenergic agonists and baclofen: Their pharmacology in the primate. Anesthesiology 54: 451-467, 1981.

117. Yaksh, T.L. \& Hammond, D.L.: Peripheral and central substances involved in the rostral transmission of nociceptive information. Pain 13: 1-86, 1982.

118. Yaksh, T.L., Howe, J.R. \& Harty, G.J.: Pharmacology of spinal pain modulatory systems. In Benedetti et al. (Eds): Advances in pain research and therapy 7, Raven Press, New York, 1984, pp 57-70.

119. Yaksh, T.L., Dirksen, R. \& Harty, G.J.: Antinociceptive effects of intrathecally injected cholinomimetic drugs in the rat and cat. Eur $J$ Pharmacol 117: 81-88, 1985.

120. Yaksh, T.L., Noueihed, R.Y. \& Durant, P.A.C.: Studies of the pharmacology and pathology of intrathecally administered 4anilinopiperidine analogues and morphine in the rat and cat. Anesthesiology 64: 54-66, 1986.

121. Zenz, M., Piepenbrock; S., Schappler-Scheele, B. \& Husch, M.: Peridurale Morphin-Analgesie II: Karzinomschmerzen. Anaesthesist 30: 508-513, 1981.

\section{CORRESPONDENCE:}

Dr..S. Sjöström

Department of Anesthesiology and Intensive Care

University Hospital

S-751 85 Uppsala

Sweden 